\title{
Avaliação lectino-histoquímica de fígado e rim de ovinos com fotossensibilização causada por Brachiaria decumbens ${ }^{1}$
}

\author{
Samay Z.R. Costa ${ }^{2 *}$, Pedro B. Nespoli ${ }^{3}$, Pedro S. Bezerra Júnior ${ }^{4}$, Vivian A. Nogueira ${ }^{5}$, David \\ Driemeier ${ }^{6}$, Fabiana M. Boabaid ${ }^{6}$, Paulo V. Peixoto ${ }^{7}$, Aníbal M. Armién ${ }^{8}$ e Ticiana N. França ${ }^{5}$
}

\begin{abstract}
Costa S.Z.R., Nespoli P.B., Bezerra Júnior P.S., Nogueira V.A., Driemeier D., Boabaid F.M., Peixoto P.V., Armién A.M. \& França T.N. 2013. [Lectin histochemistry evaluation of liver and kidney of sheep with photosensitization caused by Brachiaria decumbens.] Avaliação lectino-histoquímica de fígado e rim de ovinos com fotossensibilização causada por Brachiaria decumbens. Pesquisa Veterinária Brasileira 33(8):955-962. Departamento de Epidemiologia e Saúde Pública, Instituto de Veterinária, Universidade Federal Rural do Rio de Janeiro, Seropédica, RJ 23890-000, Brazil. E-mail: samayzillmann@gmail.com

Inspite that Brachiaria spp. are most important forage grasses for beef cattle raising in Brazil, they can under certain conditions be toxic, cause outbreaks of hepatogenic photosensibilization and determine severe economic losses. Animals grazing toxic Brachiaria spp. commonly show in their liver foamy macrophages, isolated or grouped together, and crystals inside the biliary ducts. Steroidal saponins have been identified in these crystals and are liable for damage the liverleading to accumulation of phylloerytrin. Occasionally negative images of the crystals may be seen in the cytoplasm of foamy macrophages. The pathogenesis of formation and the type of material stored in the foamy cells is still unknown. The lectin histochemistry aims to assist in the detection of foamy macrophages and consequently in the diagnosis of the poisoning. Lectin histochemistry detects what kind of specific sugar residues exists in the cytoplasm of the foamy cells. The purpose of the present study was to identify the most suitable lectins the detection of steroidal saponins in the liver and kidney of sheep with photosensitization caused by Brachiara decumbens. Fragments of liver and kidney of fifteen sheep of both sexes and variable age, from Conceição do Mato Dentro, Minas Gerais, southeastern Brazil, and one sheep kept free grazing Brachiaria spp. were evaluated by lectin histochemistry. Fourteen lectins were used (Con-A, DBA, SBA, PNA, SJA, RCA-I, UEA-I, WGA, SWGA, GSL, PSA, PHA-L, PHA-E and LCA). It was found that the PNA lectin detected in the liver of sheep with photosensitization, caused by ingestion of Brachiaria decumbens, showed specificity and great binding reactivity for foamy macrophages, and also specificity and slight binding reactivity for hepatocytes. The WGA lectin showed specificity and moderate binding reactivity for foamy macrophages of the liver, and also specificity and slight binding reactivity for hepatocytes. The SBA, GSL and LCA lectins showed specificity and moderate binding reactivity for foamy macrophages, but were not specific for hepatocytes. The PNA lectin showed greater binding reactivity in the kidney of the sheep. Lectin histochemistry evaluation had not yet been performed in liver and kidney of sheep with photosensitization caused by Brachiaria spp.
\end{abstract}

INDEX TERMS: Brachiaria decumbens, photosensitization, lectin histochemistry, liver, kidney, sheep.

\footnotetext{
${ }^{1}$ Recebido em 14 de janeiro de 2013.

Aceito para publicação em 5 de maio de 2013.

Parte da Dissertação de Mestrado do primeiro autor. Programa de Pós-Graduação em Medicina Veterinária, Universidade Federal Rural do Rio de Janeiro (UFRRJ), Seropédica, RJ.

${ }^{2}$ Curso de Pós-Graduação em Medicina Veterinária, Instituto de Veterinária, UFRRJ, Seropédica, RJ 23890-000, Brasil. *Autor para correspondência: samayzillmann@gmail.com

${ }^{3}$ Depto Clínica Médica Veterinária, Universidade Federal de Mato Grosso (UFMT), Av. Fernando Corrêa s/no, Cuiabá, MT 78065-200, Brasil.
} 
RESUMO.- Embora sejam as forrageiras mais importantes para a pecuária de corte (bovinocultura de corte) no Brasil, em certas épocas ou condições, Brachiaria spp. podem ser tóxicas e causar surtos de fotossensibilização hepatógena que determinam significativas perdas econômicas. Animais que se alimentam em pastos de Brachiaria spp. comumente apresentam macrófagos espumosos isolados ou agrupados, além de cristais no interior de ductos biliares. Saponinas esteroidais têm sido identificadas nestes cristais e são responsabilizadas por lesar o fígado levando ao acúmulo de filoeritrina. Por vezes, imagens negativas desses cristais podem estar presentes no citoplasma de macrófagos espumosos. A patogênese de formação e o tipo de material armazenado nas células espumosas ainda são desconhecidos. A técnica de lectino-histoquímica visa auxiliar na detecção desses macrófagos e, consequentemente, no diagnóstico, além de identificar quais os resíduos de açúcares específicos que estão presentes no citoplasma das células espumosas. Assim, este trabalho teve por objetivo identificar quais lectinas são mais indicadas na detecção de saponinas esteroidais no fígado e rim de ovinos com fotossensibilização causada por Brachiaria decumbens. Fragmentos de fígado e rim de quinze ovinos, de ambos os sexos e idade variável, oriundos de Conceição do Mato Dentro, Minas Gerais, e um ovino mantido em pastagem livre de Brachiaria spp. foram avaliados pela técnica de lectino-histoquímica. Quatorze lectinas foram utilizadas (Con-A, DBA, SBA, PNA, SJA, RCA-I, UEA-I, WGA, SWGA, GSL, PSA, PHA-L, PHA-E e LCA). Verificou-se que, no fígado de ovinos com fotossensibilização provocada pela ingestão de Brachiaria decumbens, a lectina PNA apresentou especificidade e acentuada reatividade aos macrófagos espumosos, bem como especificidade e leve reatividade aos hepatócitos; a lectina WGA teve especificidade e moderada reatividade aos macrófagos espumosos do fígado e especificidade e leve reatividade aos hepatócitos; e as lectinas SBA, GSL e LCA apresentaram especificidade e moderada reatividade aos macrófagos espumosos, entretanto, não foram específicas para hepatócitos. No rim dos ovinos, a lectina PNA foi a que apresentou maior reatividade. Avaliações lectino-histoquímicas ainda não haviam sido realizadas em fígado e rim de ovinos com fotossensibilização provocada por Brachiaria spp.

TERMOS DE INDEXAÇÃO: Brachiaria decumbens, fotossensibilização, lectino-histoquímica, fígado, rim, ovino.

\section{INTRODUÇÃO}

No Brasil, surtos de fotossensibilização hepatógena em bovinos e ovinos determinam perdas econômicas muito significativas, não tanto pelas mortes, mas, em especial, pela queda, temporária ou não, da produtividade. Há ainda relatos de fotossensibilização em caprinos e búfalos. Em equinos, os casos são raros (Barbosa et al. 2006).

Lectinas são proteínas ou glicoproteínas de origem não imune com um ou mais sítios de ligação por subunidade, que se unem reversivelmente a resíduos específicos de carboidratos (glicoproteínas, glicolipídeos e glicosaminoglicanos) (Goldstein et al. 1980, Lis \& Sharon 1998), e aglutinam células e/ou precipitam polissacarídeos ou glicoconjugados (Goldstein et al. 1980).
A detecção de princípios tóxicos de plantas, de forma geral, por meio de análises químicas (Burakovas et al. 2007) de tecidos animais e plantas é excessivamente trabalhosa, demanda muito tempo e implica em elevados custos. Por outro lado, a utilização da lectino-histoquímica pode detectar algumas substâncias no tecido sobre o qual ocorre a lesão e permite estabelecerem-se correlações entre a sua presença, a quantidade e a gravidade e extensão do processo. Já há algum tempo demonstrou-se a utilidade da lectino-histoquímica na deteç̧ão de substâncias complexas que contêm açúcar em tecidos animais relacionadas ou não com doenças do armazenamento como as glicoproteinoses (ex: manosidose) (Driemeier et al. 2000, Armién et al. 2007) e as glicolipidoses (ex: gangliosidose, galactosidose) (Alroy et al. 1986, Murname et al. 1989). Gomar e colaboradores (2005), por meio da lectino-histoquímica, detectaram resíduos de carboidratos que se acumulam no citoplasma de macrófagos espumosos em tecidos de bovinos de matadouro, sem fotossensibilação, que se alimentavam em pastos de Brachiaria decumbens e B. brizantha. As lectinas Arachis hypogaea agglutinin (PNA), Triticum vulgaris agglutinin (WGA) e Glycine Max agglutinin (SBA) foram as que demonstraram maior afinidade pelos macrófagos espumosos. Este estudo abriu excelentes possibilidades para investigação de doenças, inclusive com etiologia desconhecida, que sejam determinadas pela ingestão de substâncias tóxicas. Fígados e linfonodos de ovinos, sem fotossensibilização, que se alimentavam exclusivamente de Brachiaria spp. também foram avaliados pela técnica de lectino-histoquímica. As lectinas Concanavalia ensiformis agglutinin (Con-A), Ricinus communis agglutinin (RCA), Triticum vulgaris agglutinin (WGA), Lens esculenta (LCA) e Phaseolus vulgaris (PHA-L) foram as que apresentaram reatividade mais acentuada em macrófagos espumosos (Boabaid et al. 2011).

Embora estudo similar já tenha sido feito em bovinos (Gomar et al. 2005) e em ovinos (Boabaid et al. 2011) que ingeriram Brachiaria spp., trata-se aqui de estudo lectino-histoquímico realizado em ovinos afetados por esta planta que de fato desenvolveram fotossensibilização. Desta forma procura-se correlacionar o padrão lectino-histoquimíco com a severidade da lesão hepática e o aparecimento de fotossensibilização.

\section{MATERIAL E MÉTODOS}

Animais. Quinze ovinos mestiços de Santa Inês com Texel, de ambos os sexos, de idade variável, morreram intoxicados naturalmente por Brachiaria decumbens entre os anos de 2007 e 2008 em Conceição do Mato Dentro, no Estado de Minas Gerais. Os ovinos morreram a campo e foram necropsiados pelo veterinário encarregado da fazenda, que fez a coleta de fragmentos de fígado e rim, porém sem proceder a descrição da necropsia. Os fragmentos foram fixados em formalina a $10 \%$ tamponada. Utilizamos, também, os mesmos tecidos de controles negativos provenientes de um ovino mantido em pastagem livre de Brachiaria spp.

Lectinas. Seções histológicas do fígado e rim do ovino controle e dos 15 ovinos com fotossensibilização foram desparafinadas, hidratadas, e incubadas por 30 minutos em peróxido de hidrogênio a 3\% para bloqueio de peroxidases endógenas. Após a lavagem das lâminas por dois minutos com tampão fosfato (PBS), estas ficaram submersas em tampão citrato (pH 6,0) para recuperação antigênica, 
por 40 minutos a 96ㅇ $\mathrm{C}$ em panela de pressão digital. 0 bloqueio de reações inespecíficas foi realizado com leite desnatado a 5 \% (Molico ${ }^{\circledR}$ - Indústria Brasileira). Os cortes foram incubados "overnight" com lectinas (Vector Laboratories, Burlingame, Califórnia, 94010, USA) na diluição de $5 \mu \mathrm{g} / \mathrm{mL}$ em PBS, com exceção das lectinas Con A e RCA, que foram diluídas nas proporções de $0,5 \mu \mathrm{l} / \mathrm{ml}$ e $1 \mu \mathrm{l} / \mathrm{ml}$, respectivamente. Utilizamos as lectinas Canavalia ensiformis agglutinin (Con-A; a-d-Man; a-d-Glc-específica), Dolichos biflorus agglutinin (DBA; a-d-Gal-Nac-especifica), Glycine max agglutinin (SBA; a-d-GalNac; b-Gal-específica), Arachis hypogaea agglutinin (PNA; b-d-Gal/(1-3)GalNAc-específica), Ricinus communis agglutinin-I (RCA - I; b-d-Gal-específica), Ulex europaeus agglutinin-I (UEA-1; a-L-Fuc-específica), Triticum vulgaris agglutinin (WGA; a-d-GlcNAc/ NeuNAc-específica), Succinyl-WGA (sWGA GalNAc-específica), Griffonia (Bandeiraea) simplicifolia (GSL $\alpha \mathrm{Gal}, \alpha \mathrm{GalNAc}$ específica), Sophora japonica (SJA $\beta$-GalNAc específica), Pisum sativum (PSA $\alpha$ Man, $\alpha$ Glc específica), Phaseolus vulgaris (PHA-L Gal $\beta 4$ GlcNAc $\beta 6$, Man $\alpha 3$ específica e PHA-E Galß4GlcNAc $\beta 2$ Man $\alpha 6$, Man $\beta 4$ específica), Lens culinaris ou L. esculenta (LCA $\alpha$ Man, $\alpha$ Glc) (Lectin Kit Biotinylated BK 1000 e 2000, Vector Laboratories Inc., Burlingame, CA, USA), e posteriormente incubamos com o complexo avidina-biotina-peroxidase (Vector Laboratories Inc.) por 20 minutos. Utilizou-se o cromógeno diaminobenzidina (DAB) e todas as seções foram contracoradas com hematoxilina de Harris.

Microscopia eletrônica de transmição. Após a fixação em formol tamponado a $10 \%, 1 \mathrm{~mm}^{3}$ do fígado foi refixado em glutaraldeído tamponado a 3\%, em solução de cacodilato de sódio a 0.166 M (Electron Microscopy Sciences, Hatfield, Pennsylvania), seguido de uma segunda refixação em tetróxido de ósmio a $1 \%$. 0 tecido foi desidratado em uma bateria de álcool e incluído em resina (Electron Microscopy Sciences). As amostras foram emblocadas e cortadas em um ultramicrótomo Leica UC6 (Leica Microsystems). Os cortes $(60-90 \mathrm{~nm})$ foram coletados em grades de cobre de 100-mesh (Electron Microscopy Sciences), contrastados com acetato de uranila a 5\% por 20 minutos e lavados por solução de citrato de Satos' por 6 minutos. As secções foram examinadas em um microscópio eletrônico de transmissão (JEOL Ltd., Tokyo, Japan). As dimensões das estruturas celulares foram analizadas através do software iTEM (Olympus SIS, Munster, Germany).

\section{RESULTADOS}

\section{Achados macroscópicos}

0 exame dos fragmentos teciduais, fixados em formalina, revelou variável, porém muito evidente, coloração esverde- ada tanto no fígado quanto no rim. Adicionalmente no fígado de alguns animais havia acentuação do padrão lobular.

\section{Histopatologia}

No fígado observaram-se macrófagos espumosos isolados ou, mais raramente, em grupos de duas ou três células distribuídos de forma aleatória (Fig.1), tumefação e vacuolização de hepatócitos, necrose individual de hepatócitos, pericolangite crônica, leve proliferação de ductos biliares, retenção biliar e fibrose periportal. Em dois casos foi possível observar imagens negativas de cristais no interior de ductos biliares.

No rim havia presença de glóbulos eosinofílicos no espaço de Bowman, dilatação de alguns túbulos do córtex, aumento do filtrado glomerular, tumefação, vacuolização e glóbulos eosinofílicos no citoplasma das células epiteliais dos túbulos uriníferos e leve congestão. Em dois animais imagens negativas de cristais e bile estavam presentes no interior de túbulos uriníferos.

O detalhamento das lesões microscópicas de cada animal está sintetizado nos Quadros 1 e 2.

\section{Avaliação lectino-histoquímica}

Os resultados da avaliação lectino-histoquímica estão resumidos nos Quadros 3 e 4. A lectina PNA apresentou

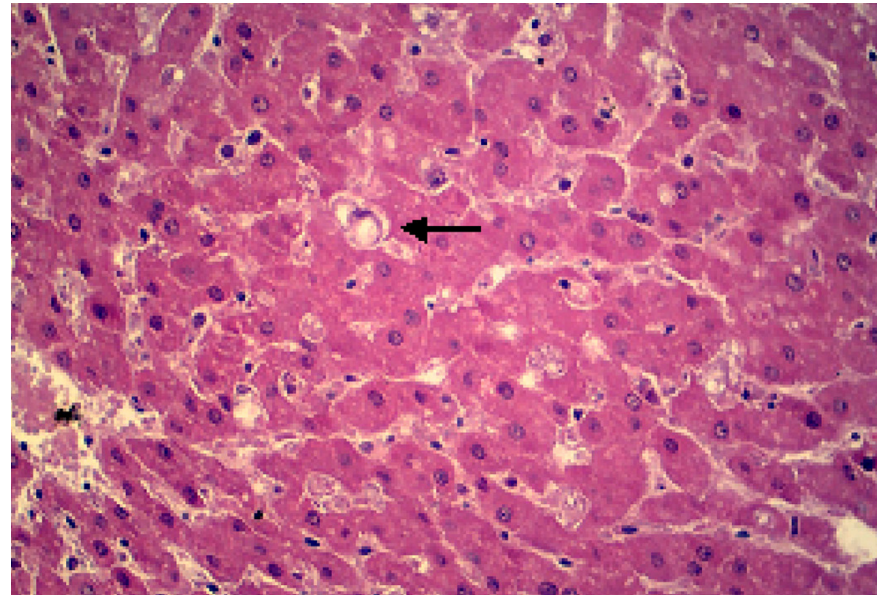

Fig.1. Fígado com macrófagos espumosos isolados (seta) de ovino com fotossensibilização (SAP 31229). HE, obj.20x.

Quadro 1. Avaliação histológica dos fígados dos ovinos com fotossensibilização por Brachiaria decumbens

\begin{tabular}{|c|c|c|c|c|c|c|c|c|c|c|}
\hline \multirow[t]{2}{*}{ SAP } & \multicolumn{4}{|c|}{ Hepatócitos } & \multirow{2}{*}{$\begin{array}{l}\text { Macrófagos } \\
\text { espumosos }\end{array}$} & \multirow{2}{*}{$\begin{array}{c}\text { Proliferação dos } \\
\text { ductos biliares }\end{array}$} & \multirow{2}{*}{$\begin{array}{l}\text { Retenção } \\
\text { biliar }\end{array}$} & \multirow{2}{*}{$\begin{array}{l}\text { Pericolangite } \\
\text { mononuclear }\end{array}$} & \multirow{2}{*}{$\begin{array}{c}\text { Fibrose } \\
\text { periportal }\end{array}$} & \multirow[t]{2}{*}{ Congestão } \\
\hline & Tumefação & Vacuolização & Necrose ${ }^{* *}$ & Binucleados & & & & & & \\
\hline 31216 & $+(+)^{*}$ & + & + & + & $++(+)$ & + & + & + & + & - \\
\hline 31217 & + & - & + & - & ++ & - & + & + & + & - \\
\hline 31218 & + & $(+)$ & - & $(+)$ & ++ & $(+)$ & - & - & $(+)$ & - \\
\hline 31219 & + & $(+)$ & - & + & $++(+)$ & - & - & $(+)$ & + & - \\
\hline 31220 & + & + & - & - & ++ & - & $(+)$ & $(+)$ & $(+)$ & $(+)$ \\
\hline 31221 & - & - & + & - & ++ & + & $(+)$ & $(+)$ & + & $(+)$ \\
\hline 31222 & $(+)$ & - & $(+)$ & - & ++ & $(+)$ & - & $(+)$ & + & + \\
\hline 31223 & $(+)$ & - & $(+)$ & + & $++(+)$ & + & - & $+(+)$ & + & - \\
\hline 31224 & $+(+)$ & - & - & $(+)$ & ++ & $(+)$ & - & + & - & - \\
\hline 31225 & - & - & $(+)$ & - & $+(+)$ & - & - & - & - & $(+)$ \\
\hline 31226 & $(+)$ & - & $(+)$ & + & $++(+)$ & $(+)$ & - & + & + & - \\
\hline 31227 & $(+)$ & $(+)$ & $(+)$ & $(+)$ & ++ & - & - & - & - & - \\
\hline 31228 & - & - & - & $(+)$ & $+(+)$ & $(+)$ & $(+)$ & ++ & - & - \\
\hline 31229 & + & - & $(+)$ & + & ++ & - & - & - & $(+)$ & + \\
\hline 31230 & + & + & $(+)$ & $(+)$ & ++ & ++ & + & - & $++(+)$ & - \\
\hline
\end{tabular}

*++ Lesão moderada, + lesão leve, (+) lesão discreta, - lesão ausente. ** Necrose individual de hepatócitos. 
Quadro 2. Avaliação histológica dos rins dos ovinos com fotossensibilização por B. decumbens

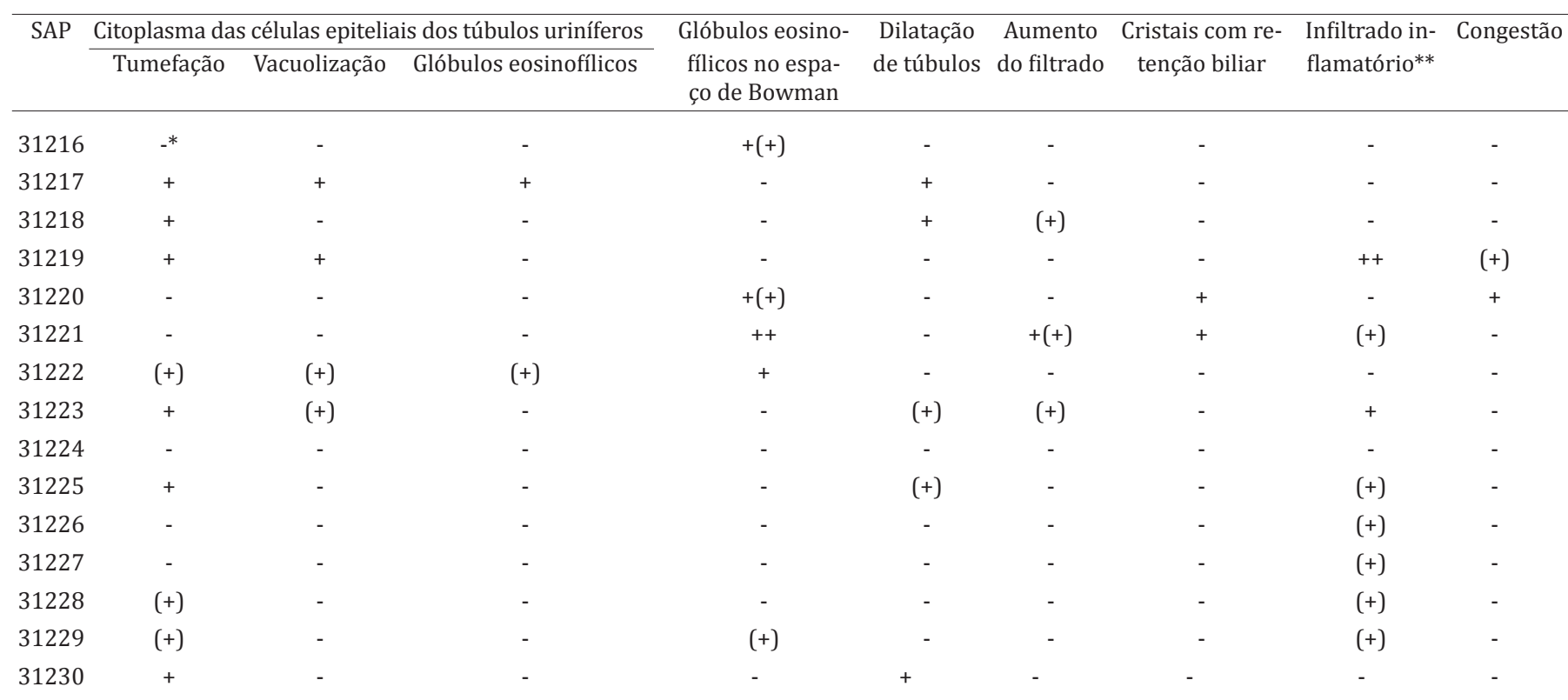

*++ Lesão moderada, + lesão leve, (+) lesão discreta, - lesão ausente. ** Infiltrado inflamatório mononuclear.

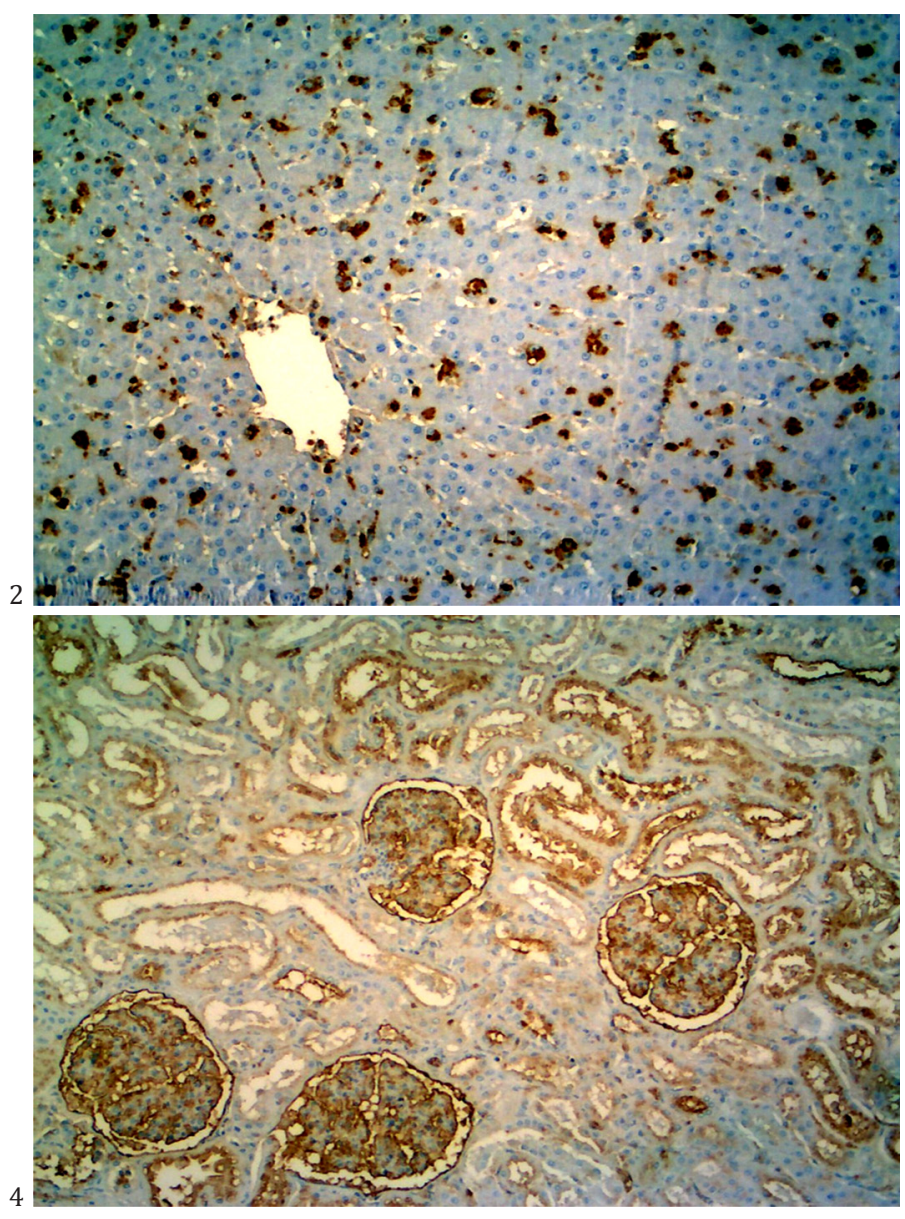

Fig.2. Acentuada reatividade para lectina PNA em macrófagos no fígado de ovino com fotossensibilização (SAP 31218). Obj.10x.

Fig.4. Acentuada reatividade à lectina PNA na membrana basal dos glomérulos e nos túbulos do córtex renal de ovino com fotossensibilização (SAP 31230). Obj.10x.
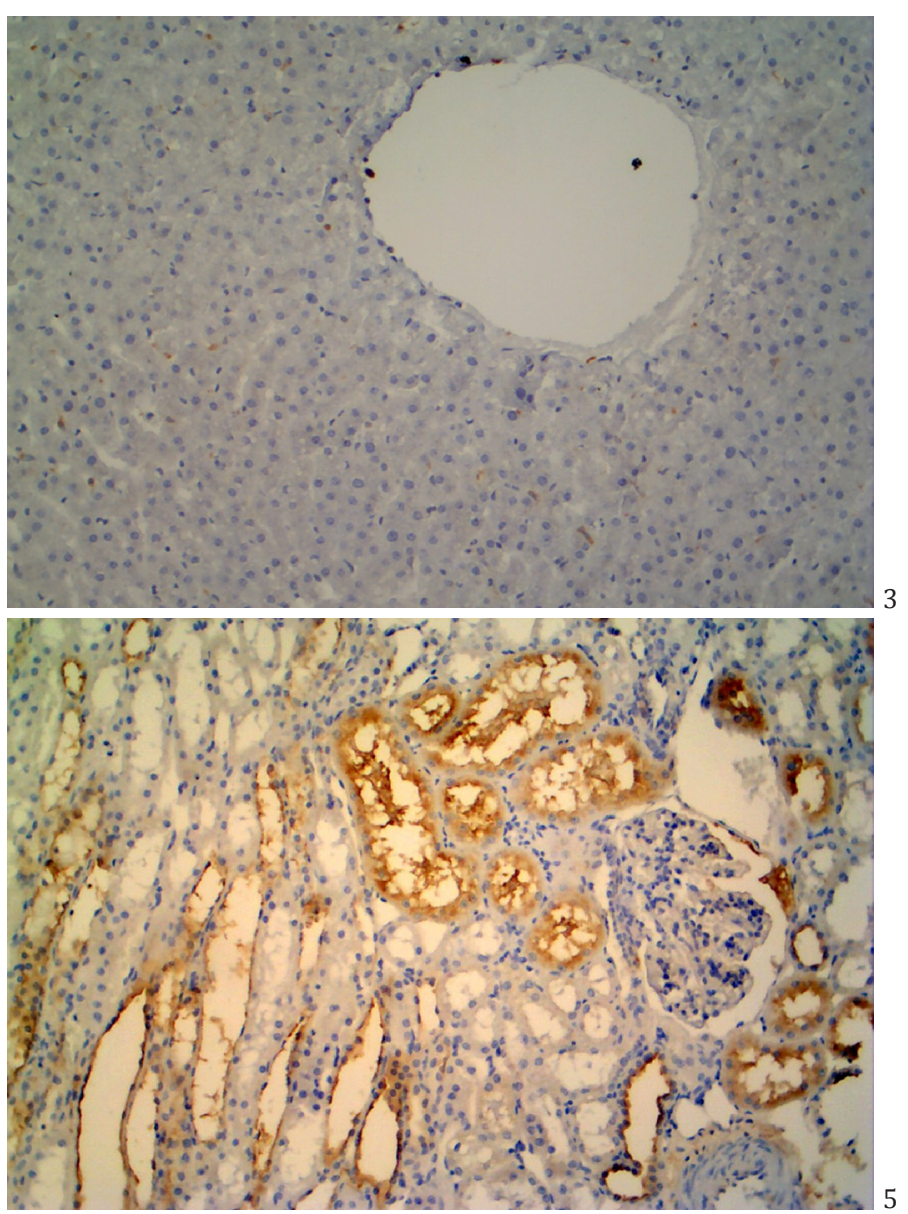

Fig.3. Controle negativo, ovino. Ausência de reatividade no fígado à lectina PNA. Obj. 10x.

Fig.5. Controle negativo, ovino. Reatividade leve a moderada de alguns túbulos do córtex renal à lectina PNA. Obj. 20x. 
Quadro 3. Avaliação lectino-histoquímica do fígado de ovinos com fotossensibilização por B. decumbens

\begin{tabular}{|c|c|c|c|c|c|c|c|}
\hline & Macrófagos & Hepatócitos & Ducto biliar & $\begin{array}{l}\text { Conteúdo do } \\
\text { ducto biliar }\end{array}$ & $\begin{array}{c}\text { Superfície do } \\
\text { ducto biliar }\end{array}$ & Íntima do vaso & $\begin{array}{c}\text { Tecido } \\
\text { conjuntivo }\end{array}$ \\
\hline \multirow[t]{2}{*}{ PNA } & $+++^{*}$ & + & - & ++ & - & - & - \\
\hline & $(15 / 15)$ & $(13 / 15)$ & & $(11 / 15)$ & - & - & - \\
\hline \multirow[t]{2}{*}{ WGA } & ++ & + & - & $++/+++$ & + & + & - \\
\hline & $(15 / 15)$ & $(15 / 15)$ & - & $(7 / 15)$ & $(3 / 15)^{* *}$ & $(2 / 15)^{* *}$ & - \\
\hline \multirow[t]{2}{*}{ SBA } & ++ & + & ++ & $++/+++$ & - & - & - \\
\hline & $(15 / 15)$ & $(15 / 15)^{* *}$ & $(5 / 15)^{* *}$ & $(4 / 15)^{* *}$ & - & - & - \\
\hline \multirow[t]{2}{*}{ GSL } & ++ & + & - & $+/++$ & - & - & - \\
\hline & $(15 / 15)$ & $(15 / 15)^{* *}$ & - & $(7 / 15)$ & - & - & - \\
\hline \multirow[t]{2}{*}{ LCA } & ++ & + & - & - & - & - & - \\
\hline & $(15 / 15)$ & $(11 / 15)^{* *}$ & - & - & - & - & - \\
\hline \multirow[t]{2}{*}{ CON-A } & +++ & +++ & +++ & - & - & +++ & - \\
\hline & $(15 / 15)$ & $(15 / 15)^{* *}$ & $(15 / 15)$ & - & - & $(15 / 15)$ & - \\
\hline \multirow[t]{2}{*}{ RCA } & +++ & $++/+++$ & +++ & ++ & $++/+++$ & +++ & - \\
\hline & $(15 / 15)$ & $(15 / 15)^{* *}$ & $(15 / 15)$ & $(7 / 15)$ & $(2 / 15)^{* *}$ & $(6 / 15)^{* *}$ & - \\
\hline \multirow[t]{2}{*}{ PHA-E } & $+/++$ & + & - & $+/++$ & - & $+/++$ & + \\
\hline & $(15 / 15)$ & $(15 / 15)^{* *}$ & - & $(5 / 15)$ & - & $(5 / 15)^{* *}$ & $(3 / 15)^{* *}$ \\
\hline \multirow[t]{2}{*}{ PHA-L } & $++/+++$ & $+/++$ & - & $+/++$ & ++ & $\stackrel{++}{+}$ & ++ \\
\hline & $(13 / 15)$ & $(15 / 15)^{* *}$ & - & $(8 / 15)^{*}$ & $(3 / 15)$ & $(9 / 15)^{* *}$ & $(7 / 15)$ \\
\hline PSA & - & $+/++$ & + & - & - & + & - \\
\hline- & $(15 / 15)^{* *}$ & $(2 / 15)$ & - & - & $(3 / 15)^{* *}$ & - & \\
\hline \multirow[t]{2}{*}{ SWGA } & $+/++$ & - & - & - & - & - & - \\
\hline & $(11 / 15)$ & - & - & - & - & - & - \\
\hline \multirow{2}{*}{$\begin{array}{c}\text { DBA } \\
-\end{array}$} & - & - & +++ & - & - & - & - \\
\hline & - & $(8 / 15)^{* *}$ & - & - & - & - & \\
\hline \multirow[t]{2}{*}{ UEA } & + & +++ & +++ & +++ & +++ & - & - \\
\hline & $(3 / 15)$ & $(2 / 15)$ & $(13 / 15)^{* *}$ & $(2 / 15)$ & $(1 / 15)$ & - & - \\
\hline \multirow[t]{2}{*}{ SJA } & - & - & - & - & - & - & - \\
\hline & - & - & - & - & - & - & - \\
\hline
\end{tabular}

Quadro 4. Avaliação lectino-histoquímica do rim de ovinos com fotossensibilização por B. decumbens

\begin{tabular}{|c|c|c|c|c|c|c|c|c|}
\hline & Glomérulo & $\begin{array}{l}\text { Túbulos } \\
\text { do córtex }\end{array}$ & $\begin{array}{c}\text { Bordas em } \\
\text { escova }\end{array}$ & $\begin{array}{l}\text { Membrana basal } \\
\text { túbulos do córtex }\end{array}$ & $\begin{array}{l}\text { Túbulos da } \\
\text { medular }\end{array}$ & Filtrado & $\begin{array}{c}\text { Íntima } \\
\text { dos vasos }\end{array}$ & $\begin{array}{c}\text { Tecido } \\
\text { conjuntivo } \\
\end{array}$ \\
\hline \multirow[t]{2}{*}{ PNA } & $+++^{*}$ & $++/+++$ & $++/+++$ & - & - & - & $++/+++$ & $++/+++$ \\
\hline & $(15 / 15)$ & $(11 / 15)^{* *}$ & $(10 / 15)^{* *}$ & - & - & - & $(9 / 15)$ & $(10 / 15)$ \\
\hline \multirow[t]{2}{*}{ WGA } & $+/++$ & $++/+++$ & $++/+++$ & - & $++/+++$ & ++ & - & - \\
\hline & $(12 / 15)^{* *}$ & $(15 / 15)^{* *}$ & $(8 / 15)^{* *}$ & - & $(7 / 15)$ & $(3 / 15)$ & - & - \\
\hline \multirow[t]{2}{*}{ SBA } & - & ++ & - & ++ & - & - & - & - \\
\hline & - & $(15 / 15)^{* *}$ & - & $(11 / 15)$ & - & - & - & - \\
\hline \multirow[t]{2}{*}{ GSL } & - & $+/++$ & - & + & $+/++$ & - & - & - \\
\hline & - & $(15 / 15)^{* *}$ & - & $(3 / 15)^{* *}$ & $(3 / 15)^{* *}$ & - & - & - \\
\hline \multirow[t]{2}{*}{ LCA } & + & + & - & + & - & - & - & - \\
\hline & $(7 / 15)^{* *}$ & $(15 / 15)^{* *}$ & - & $(2 / 15)$ & - & - & - & - \\
\hline \multirow[t]{2}{*}{ CON-A } & +++ & +++ & - & +++ & $+/++$ & - & +++ & +++ \\
\hline & $(15 / 15)$ & $(15 / 15)^{* *}$ & - & $(15 / 15)^{* *}$ & $(15 / 15)^{* *}$ & - & $(15 / 15)^{* *}$ & $(15 / 15)^{* *}$ \\
\hline \multirow[t]{2}{*}{ RCA } & +++ & +++ & - & +++ & + & - & +++ & - \\
\hline & $(15 / 15)^{* *}$ & $(15 / 15)^{* *}$ & - & $(14 / 15)^{* *}$ & $(12 / 15)$ & - & $(14 / 15)^{* *}$ & - \\
\hline \multirow[t]{2}{*}{ PHA-E } & + & $++/+++$ & $+/++$ & $++/+++$ & - & - & - & - \\
\hline & $(8 / 15)^{* *}$ & $(14 / 15)^{* *}$ & $(4 / 15)^{* *}$ & $(15 / 15)^{* *}$ & - & - & - & - \\
\hline \multirow[t]{2}{*}{ PHA-L } & + & $++/+++$ & - & $++/+++$ & $++/+++$ & $++/+++$ & +++ & +++ \\
\hline & $(9 / 15)^{* *}$ & $(14 / 15)^{* *}$ & - & $(13 / 15)$ & $(7 / 15)$ & $(5 / 15)$ & (10/15) & (8/15) \\
\hline \multirow[t]{2}{*}{ PSA } & - & + & - & - & - & - & - & - \\
\hline & - & $(15 / 15)^{* *}$ & - & - & - & - & - & - \\
\hline \multirow[t]{2}{*}{ SWGA } & - & $+/++$ & - & - & - & - & - & - \\
\hline & - & $(6 / 15)$ & - & - & - & - & - & - \\
\hline \multirow[t]{2}{*}{ DBA } & - & + & - & - & + & - & - & - \\
\hline & - & $(3 / 15)$ & - & - & $(2 / 15)$ & - & - & - \\
\hline \multirow[t]{2}{*}{ UEA } & - & - & - & - & - & - & - & - \\
\hline & - & - & - & - & - & - & - & - \\
\hline \multirow[t]{2}{*}{ SJA } & - & - & - & - & - & - & - & - \\
\hline & - & - & - & - & - & - & - & - \\
\hline
\end{tabular}


acentuada reatividade e especificidade para macrófagos espumosos no fígado de ovinos com fotossensibilização (Fig.2 e 3), houve, também, especificidade e leve reatividade aos hepatócitos. A lectina WGA apresentou moderada reatividade e especificidade para macrófagos espumosos no fígado de ovinos com fotossensibilização e especificidade e leve reatividade aos hepatócitos. Já as lectinas SBA, GSL e LCA apresentaram boa reatividade (moderada) e especificidade aos macrófagos espumosos nos ovinos com fotossensibilização, entretanto, não foram específicas para hepatócitos. No rim dos ovinos com fotossensibilização a lectina PNA foi a que apresentou maior reatividade (Fig.4 e 5).

\section{Microscopia eletrônica de transmissão}

As células de Kupffer estavam aumentadas de volume, com citoplasma distendido por acúmulo de materiais eletrodensos, circundados por membrana simples e misturados com gotículas de lipídeo, além de grande quantidade de

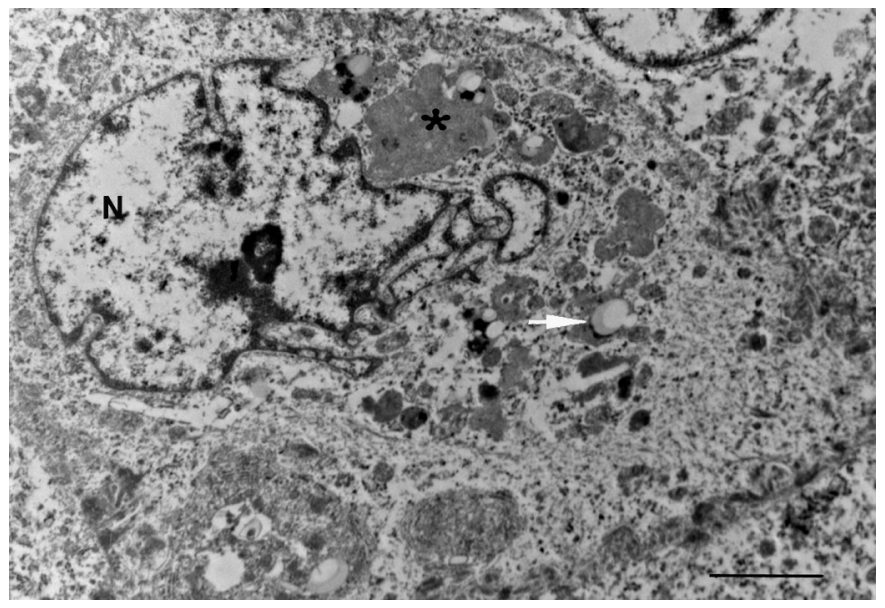

Fig.6. Ultraestrutura de um histiócito hepático afetado por saponina esteroidal. Note o núcleo $(\mathrm{N}),\left(^{*}\right)$ grandes vesículas ligadas por membranas contendo material eletrodenso e gotículas de lipídeo (seta).

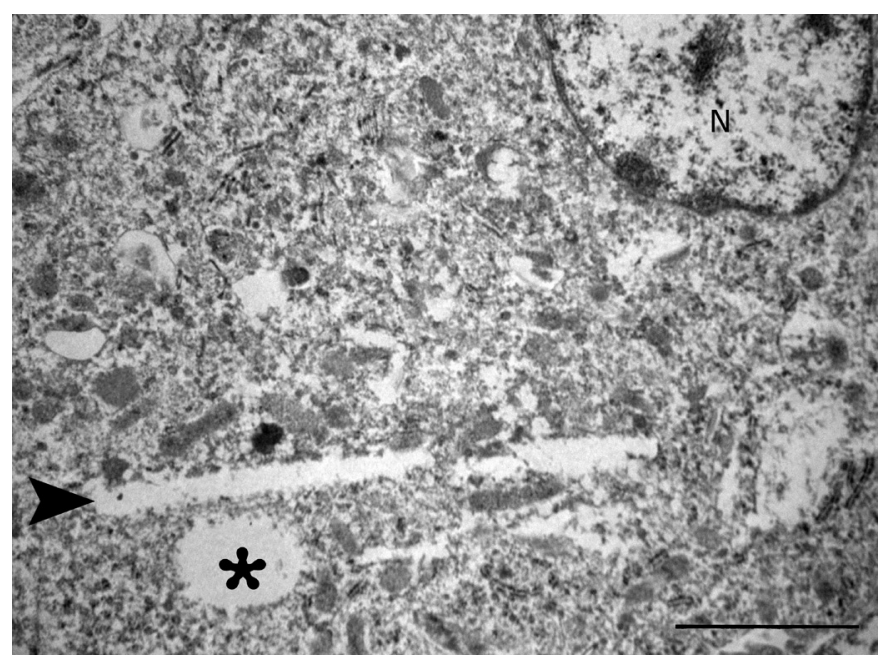

Fig.7. Ultraestrutura de um histiócito hepático afetado por saponina esteroidal. Note o núcleo $(\mathrm{N})$, e $\left(^{*}\right)$ uma gotícula de lipídeo e cristal de colesterol (cabeça de seta). filamentos intermediários semelhantes à vimentina (Fig.6). Alguns destes histiócitos residentes continham imagens negativas de cristais de colesterol (Fig.7).

\section{DISCUSSÃO}

A melhor compreensão da utilidade da lectino-histoquímica no diagnóstico de fotossensibilização determinada por agentes/plantas que contenham saponinas esteroidais, no caso as do gênero Brachiaria, passa, necessariamente, pela verificação da constância com que estes compostos impregnam os diversos tecidos de animais de diferentes espécies que as ingeriram.

No que diz respeito ao fígado de ovinos, no presente estudo, dentre as 14 lectinas testadas, a PNA revelou-se como a mais específica para marcação dos assim chamados macrófagos espumosos, células que de acordo com Driemeier et al. (1999) provavelmente contêm saponinas esteroidais misturadas a restos de hepatócitos, que, após degenerarem/necrosarem em decorrência do excesso dessas substâncias, são fagocitados. Resultado semelhante foi obtido por Gomar et al. (2005) para macrófagos espumosos contidos em fígado de bovinos de matadouro que haviam se alimentado com $B$. decumbens e $B$. brizantha. Em ovinos, por outro lado, Boabaid et al. (2011) verificaram, nesse tipo de célula, apenas uma leve reação à PNA. Não se sabe exatamente a que atribuir esta diferença de reação, mas é possível que a natureza do material fagocitado/acumulado pelos macrófagos possa variar em função da espécie de Brachiaria ingerida pelos animais ou de acordo com o tipo/proporção das saponinas armazenadas nas plantas, em decorrência da época do ano, bem como de o animal apresentar ou não fotossensibilização, da evolução clínica e do tempo de ingestão das saponinas.

No fígado dos ovinos encontramos uma moderada reatividade dos macrófagos espumosos às lectinas WGA, LCA, SBA e GSL. Já nos dois estudos acima mencionados, a lectina WGA reagiu fortemente com os macrófagos espumosos, portanto, independentemente da espécie - bovina ou ovina - apesar desta variação, pode-se considerar para efeito de diagnóstico, com base nos nossos resultados e nos resultados de Gomar et al. (2005), que os macrófagos espumosos que se formam no fígado de bovinos e ovinos, em consequência da ingestão prolongada de saponinas esteroidais, são positivos para PNA, WGA e SBA. Adicionalmente, ainda verificamos uma moderada reação dos macrófagos espumosos à GSL e LCA, lectinas não testadas por Gomar et al. (2005).

Em relação aos hepatócitos, diferentemente dos controles negativos, também observamos reatividade à PNA, porém com menor intensidade, o que parece indicar uma menor quantidade de saponinas esteroidais (ou resíduos decorrentes de seu efeito ou de sua metabolização, como por exemplo, lipoproteínas O-ligadas) nessas células do que nos macrófagos ou, alternativamente, que os resíduos/ produtos da degradação celular (organoides) induzida pelas saponinas sejam mais abundantes nos macrófagos. Por outro lado, Gomar et al. (2005) e Boabaid et al. (2011) não relataram reatividade de hepatócitos à PNA em bovinos e ovinos sem fotossensibilização. É possível que os hepatóci- 
tos de ovinos por nós estudados (que morreram em função das lesões), contivessem maiores quantidades de saponinas esteroidais (ou de resíduos decorrentes de seu efeito).

No que se refere ao rim dos ovinos, observamos moderada a intensa reatividade da PNA com o citoplasma das células epiteliais dos túbulos contorcidos do córtex e com a membrana basal de glomérulos, enquanto nos animais controle havia apenas leve a moderada reatividade em alguns poucos túbulos do córtex, de forma que, novamente, essa lectina parece importante para marcação de lesões causadas por saponinas esteroidais em tecidos. Até então não haviam sido desenvolvidos estudos com lectino-histoquímica no rim de animais pastejando ou com fotossensibilização hepatógena causada por Brachiaria spp. A forte reatividade à lectina WGA verificada no citoplasma e na borda em escova das células epiteliais dos túbulos do córtex foi considerada inespecífica, pois nos controles estas estruturas também coraram positivamente. Essas reações inespecíficas são esperadas, pois o epitélio renal se cora comumente por muitas lectinas (Barbeito et al. 2005).

Devido ao seu comportamento anfifílico e a capacidade de formar complexos com esteroides, proteínas e fosfolipídeos de membrana, as saponinas são capazes de alterar as propriedades da membrana celular, o que altera sua permeabilidade ou causa sua destruição (Schenkel et al. 2004). Drogas catiônicas anfifílicas têm sido responsabilizadas por induzirem à fosfolipidose, um acúmulo intracelular excessivo de fosfolipídeos, que pode ocorrer em qualquer tecido do corpo, mas, principalmente, na língua, fígado, rim, tecido ocular, coração, adrenal, tecido hematopoético e linfócitos circulantes. Ainda não foi possível definir o mecanismo exato da fosfolipidose induzida por drogas (Robison et al. 1985). Até o momento não foram realizadas avaliações lectino-histoquímica dessas células.

Apesar de origens bastante heterogêneas, a partir de bactérias, plantas, células animais e tecidos, a maioria das lectinas utilizadas em laboratórios pode ser divididas em cinco grupos com base na sua ligação preferencial a açúcares: (1) grupo glucose/manose; (2) grupo N-acetilglucosamina; (3) grupo galactose/ $\mathrm{N}$-acetilgalactosamina; (4) grupo L-fucose e (5) grupo ácido siálico (Damjanov 1987). Desta maneira, de acordo com os resultados obtidos, sugere-se que os macrófagos espumosos contêm quantidades significativas de galactose/ $\mathrm{N}$-acetilgalactosamina (PNA, GSL, SBA-positivas - grupo III) e quantidades um pouco menores de $\mathrm{N}$-acetilglucosamina (WGA-positiva - grupo II) e glucose/manose (LCA-positiva - grupo I). Os achados aqui observados se assemelham aos encontrados por Gomar et al. (2005), que sugerem que os macrófagos espumosos contêm quantidades significativas de $\mathrm{N}$-acetilgalactosamina.

$\mathrm{Na}$ esfingomielinose ou doença de Niemann-Pick macrófagos espumosos podem estar presentes em tecidos não nervosos, como fígado, baço, pulmão, rim, adrenal, linfonodo e tonsila (Kamiya et al. 1991). A avaliação lectino-histoquímica do fígado e baço de humanos com doença de Niemann-Pick, demonstrou que as lectinas Con-A, PNA e SBA foram as que melhor reagiram com as células afetadas (Lageron 1987), resultados parcialmente semelhantes foram encontrados neste estudo.
Uma deficiência hereditária de lipase ácida lisossomal, conhecida como doença de Wolman, Xantomatose familiar ou lipidose familiar de Wolman (Mello et al. 1982) acarreta o aparecimento de células espumosas que se agregam sob a forma de ilhotas nos sinusóides do fígado. Essa doença leva ao acúmulo de ésteres de colesterol, colesterol livre e triglicerídeo no fígado dos indivíduos acometidos. Bioquimicamente a atividade da lipase ácida lisossomal é muito baixa (Kuriwaki \& Yoshida 1999).

Assim como Gomar et al. (2005) e Boabaid et al. (2011) acreditamos que a indução da inibição da lipase ácida lisossomal possa estar envolvida na patogênese das células espumosas na intoxicação por Brachiaria spp., devido às características morfológicas e histoquímicas destas células serem semelhantes às encontradas no macrófagos na doença de Wolman.

Por fim, no que se refere aos aspectos morfológicos, as lesões histológicas observadas são similares às anteriormente verificadas em ovinos intoxicados por Brachiaria spp. (Lemos et al. 1996, Brum et al. 2007, Albernaz et al. 2010, Saturnino et al. 2010). De forma análoga, as alterações ultraestruturais dos histiócitos corados pelas lectinas são semelhantes às descritas por Driemeier et al. (1998) e foram consideradas específicas para lesões histológicas induzidas por saponinas esteroidais. A correlação dos achados ultraestruturais com o padrão lectino-histoquímico sugere que as lectinas não só tenham demonstrado material acumulado em macrófagos em forma de detritos hepatocelulares, mas também tenham evidenciado modificações de membrana, que, contudo, necessitariam ser confirmadas por estudo ultramicroscópico mais detalhado. Estudos adicionais que correlacionem essas duas técnicas, lectino-histoquímica aplicada à microscopia eletrônica, devem ser incentivados para que se possa identificar o mecanismo de formação dos macrófagos espumosos e suas alterações citoquímicas em animais que ingerem Brachiaria spp.

Contribuição dos autores.- Samay Z.R. Costa (UFRRJ), como parte de sua dissertação de mestrado, executou as técnicas de hematoxilina-eosina e de lectino-histoquímica, realizou avaliação microscópica, a revisão bibliográfica e fez a redação; Pedro B. Nespoli (UFMT) realizou a avaliação clínico-epidemiológica e coletou fragmentos de órgãos; Pedro S. Bezerra Júnior (UFLA) padronizou a técnica de lectino-histoquímica e orientou o estudo lectino-histoquímico; Vivian A. Nogueira (UFRRJ) fez avaliação microscópica e revisou a redação; David Driemeier (UFRGS) montou a técnica de lectino-histoquímica e orientou no estudo lectino-histoquímico; Fabiana M. Boabaid (UFRGS) executou a técnica de lectino-histoquímica; Paulo V. Peixoto (UFRRJ) fez avaliação microscópica e corrigiu a redação; Aníbal M. Armién (Univ. Minnesota) realizou a técnica de microscopia eletrônica e interpretou os achados; Ticiana N. França (UFRRJ) padronizou a técnica de lectino-histoquímica, orientou o estudo lectino-histoquímico, fez avaliação microscópica e corrigiu a redação do trabalho.

Agradecimentos.- Ao Sr. Miltom Lapertosa pelo apoio e por disponibilizar a infraestrutura da sua propriedade e os animais do seu rebanho para o acompanhamento do surto de fotossensibilização. Ao CNPq e à CAPES pelo suporte financeiro.

\section{REFERÊNCIAS}

Albernaz T.T., Silveira J.A.S., Silva N.S., Oliveira C.H.S., Reis A.S.B., Oliveira C.M.C., Duarte M.D. \& Barbosa J.D. 2010. Fotossensibilização em ovinos associada à ingestão de Brachiaria brizantha no estado do Pará. Pesq. Vet. Bras. 30(9):741-748. 
Alroy J., Ucci A.A., Goyal V. \& Woods W. 1986. Lectin Histochemistry of Glycolipid Storage Diseases on Frozen and Paraffin-Embedded Tissue Sections. J. Histochem. Cytochem. 34(4):501-505.

Armién A.G., Tokarnia C.H., Peixoto P.V. \& Frese K. 2007. Spontaneous and experimental glycoprotein storage disease of goats induced by Ipomoea carnea subsp. fistulosa (Convolvulaceae). Vet. Pathol. 44:170-184.

Barbeito C., Massone A.R. \& Quiroga M.A. 2005. Introduction a las técnicas de lectinhistoquímica: aplicaciones em patologia veterinária. 17ํㅡㄴ Curso Internacional de Posgrado em Técnicas de Inmunohistoquimica, Lectinhistoquimica y Microscopia Electronica, Fac., Cienc. Vet., Univ. La Plata, La Plata. 117p. (Apostilha)

Barbosa J.D., Oliveira C.M.C., Tokarnia C.H. \& Peixoto P.V. 2006. Fotossensibilização hepatógena em eqüinos pela ingestão de Brachiaria humidicola (Gramineae) no Estado do Pará. Pesq. Vet. Bras. 26(3):147-153.

Boabaid F.M., Antoniassi N.A.B., Pescador C.A., Souza M.A., Gasparetto N.D., Cruz C.E.F., Bezerra Júnior P.S., Driemeier D. \& Colodel E.M. 2011. Lectin histochemistry on sections of liver and hepatic lymph nodes from sheep grazing on Brachiaria spp., p.124-128. In: Riet-Correa F., Pfister J., Schild A.L. \& Wierenga T. (Eds), Poisoning by Plants, Mycotoxins and Related Toxins. CAB International, London.

Brum K.B., Haraguchi M., Lemos R.A.A., Riet-Correa F. \& Fioravanti M.C.S. 2007. Crystal-associated cholangiopathy in sheep grazing Brachiaria decumbens containing the saponin protodioscin. Pesq. Vet. Bras. 27(1):39-42.

Burakovas R.G., Yokosuka A., Mimaki Y., Riet-Correa F., Medeiros R.M.T., Dantas A.F.M., Matos P.F., Katiki L.M., Veríssimo C.J., Bueno M.S., Brum K.B., Fioravanti M.C.S., Barbosa Neto J.D. \& Haraguchi M. 2007. Investigação das saponinas furostânicas nas gramíneas de Panicum. 30ª Reunião Anual da Sociedade Brasileira de Química, São Paulo.

Damjanov I. 1987. Biology of disease, lectin cytochemistry and histochemistry. Laboratory investigation 57(1):5-19.

Dennis L.W., Granovsky M. \& Warren C.E. 1999. Glycoprotein glycosylation and cancer progression. Biochimica et Biophysica Acta 1473:21-34.

Driemeier D., Colodel E.M., Gimeno E.J. \& Barros S.S. 2000. Lysosomal storage disease caused by Sida carpinifolia poisoning in goats. Vet. Pathol. 37:153-159.

Driemeier D., Barros S.S., Peixoto P.V., Tokarnia C.H., Döbereiner J. \& Brito M.F. 1998. Estudos histológico, histoquímico e ultra-estrutural de fígados e linfonodos de bovinos com presença de macrófagos espumosos ("foam cells"). Pesq. Vet. Bras. 18(1):19-34.
Driemeier D., Döbereiner J., Peixoto P.V. \& Brito M.F. 1999. Relação entre macrófagos espumosos ("foam cells") no fígado de bovinos e ingestão de Brachiaria spp. no Brasil. Pesq. Vet. Bras. 19(2):79-83.

Goldstein I.J., Hughes R.C., Monsigny M., Osawa T. \& Sharon N. 1980. What should be called a lectin? Nature 285:66.

Gomar M.S., Driemeier D., Colodel E.M. \& Gimeno E.J. 2005. Lectin Histochemistry of foam cells in tissues of cattle grazing Brachiaria spp. J. Vet. Med. A 52:18-21.

Kamiya S., Yamagami T., Umeda M., Sugiyama M. \& Daigo M. 1991. Lectin histochemistry of foamy cells in non-nervous tissues of feline sphingomyelinosis. J. Comp. Pathol. 105:241-245.

Kuriwaki K. \& Yoshida H. 1999. Morphological characteristics of lipid accumulation in liver-constituting cells of acid lipase deficiency rats (Wolman's disease model rats). Pathol. Int. 49:291-297.

Lageron A. 1987. Characterization by lectin binding of the sugar moiety of glycocompounds stored in inherited diseases. Histochemical J. 19:419425.

Lemos R.A.A., Ferreira L.C.L., Silva S.M., Nakazato L. \& Salvador S.C. 1996. Fotossensibilização e colangiopatia associada a cristais em ovinos em pastagens com Brachiaria decumbens. Ciência Rural 26(1):109-113.

Lis H. \& Sharon N. 1998. Lectins: carbohydrate-specific proteins that mediate cellular recognition. Chem. Rev. 98:637-674.

Mello A.M., Ellinguer F., Lourenço L.A.P., Castro L.M.S. \& Zimmerman M.A.T. 1982. Doença de Wolman (xantomatose familiar), relato de caso. Pediatria, S. Paulo, 4:159-162.

Murname R.D., Ahern-Rindell A.J. \& Prieuer D.J. 1989. Lectin histochemistry of an ovine lysosomal storage disease with deficiencies of betagalactosidase and alfa-neuraminidase. Am. J. Pathol. 135(4):623-630.

Robison R.L., Visscher G.E., Stanley A.R., Engstron R.G., Hartman H.A. \& Ballard F.H. 1985. Generalized phospholipidosis by an amphiphilic cationic psychotropic drug. Toxicologic Pathology 13(4):335-348.

Saturnino K.C., Mariani T.M., Barbosa-Ferreira M., Brum K.B., Fernandes C.E.S. \& Lemos R.A.A. 2010. Intoxicação experimental por Brachiaria decumbens em ovinos confinados. Pesq. Vet. Bras. 30(3):195-202.

Schenkel E.P., Gosmann G. \& Athayde M.L. 2004. Saponinas, p.711-740. In: Simões C.M.O., Schenkel E.P., Gosmann G., Melo J.C.P., Mentz L.A. \& Petrovick P.R. (Eds), Farmacognosia da Planta ao Medicamento. UFRGS, Porto Alegre. 